\title{
Low folate levels are associated with methylation-mediated transcriptional repression of miR-203 and miR-375 during cervical carcinogenesis
}

\author{
MIN HAO, WEIHONG ZHAO, LILI ZHANG, HONGHONG WANG and XIN YANG \\ Department of Obstetrics and Gynecology, The Second Hospital of Shanxi Medical University, \\ Taiyuan, Shanxi 030001, P.R. China
}

Received January 23, 2015; Accepted January 22, 2016

DOI: $10.3892 / \mathrm{ol} .2016 .4449$

\begin{abstract}
The aim of the present study was to investigate the correlation between a lack of folic acid and the abnormal expression of microRNA (miR)-203 and miR-375 in cervical cancer. In total, 60 tissue samples of cervical intraepithelial neoplasia (CIN) or stage IA-IIA cervical cancer (study group), and 30 samples without soluble interleukin or malignancy (control group) were examined. The expression of miR-203 and miR-375 was detected using reverse transcription-quantitative polymerase chain reaction (RT-qPCR), and the difference in expression levels was quantified using the $2^{-\Delta \Delta \mathrm{Cq}}$ method. In addition, CaSki cervical cancer cells were cultured in vitro and treated with various concentrations of folic acid. The DNA methylation states of miR-203 and miR-375 were subsequently detected by methylation-specific PCR, and the expression levels were evaluated using RT-PCR. miR-203 and miR-375 were significantly downregulated in CIN and cervical cancer tissues, compared with the control group. There was a marked difference in terms of the expression levels of miR-375 between the two groups $(\mathrm{P}<0.05)$. In CaSki cells, as the concentration of folic acid increased, the positive rate of DNA methylation of miR-203 and miR-375 decreased, while the expression levels of miR-203 and miR-375 demonstrated a gradual increase, which indicated that the latter two parameters were negatively correlated $(\mathrm{P}<0.05)$. Compared with normal cervical tissue, the expression levels of miR-203 and miR-375 were downregulated in CIN and cervical cancer. Methylation of these two miRs was apparent in CaSki cells, and was associated with a lack of folic acid. Therefore, reduced levels of folic acid, leading to increased methylation of miR-203 and miR-375, may be significant events during cervical carcinogenesis.
\end{abstract}

Correspondence to: Dr Min Hao, Department of Obstetrics and Gynecology, The Second Hospital of Shanxi Medical University, 382 Wuyi Road, Taiyuan, Shanxi 030001, P.R. China

E-mail:minhaocn@126.com

Key words: cervical cancer, folic acid, microRNA-203, microRNA-375, methylation

\section{Introduction}

Cervical cancer is one of the most common malignancies in women worldwide, and remains one of the leading causes of cancer-associated mortalities globally (1). Epidemiological studies show that human papillomavirus (HPV) infection, in particular HPV16, is relevant in the onset of cervical cancer (2). However, an increasing body of evidence has indicated that the occurrence of cervical cancer is a result of the combined action of multiple factors, since the incidence of HPV infection in women of childbearing age is higher, but the incidence of cervical cancer is lower among these patients (3). Therefore, HPV infection is not the only factor involved in the development of cervical cancer $(4,5)$. Following infection with high-risk HPV, cervical cancer develops through precancerous lesions termed cervical intraepithelial neoplasia (CIN), and eventually progresses to invasive cervical cancer. To the best of our knowledge, the molecular mechanisms underlying the progression of HPV infection to cervical cancer largely remain to be elucidated.

Previous studies have demonstrated that the deregulation of microRNAs (miRs) contributes to the process of cervical carcinogenesis (6). miRs are small non-coding RNA molecules that are able to bind to the 3'-untranslated region of their target messenger (m)RNA, thus regulating the stability and translation of mRNAs, which results in the inhibition of translation or degradation of the target mRNA (7). Due to their ability to alter the expression of protein-coding oncogenes and tumor suppressor genes, miRs are proposed to have a significant role in cancer development (8). Similar to various growth-suppressive protein-encoding tumor suppressor genes, certain miR genes harbor $\mathrm{CpG}$ islands, which are susceptible to methylation-mediated silencing $(9,10)$. Therefore, hypermethylation-mediated silencing of tumor-suppressive miRs may be an important mechanism of tumorigenesis (11).

Folate is a methyl donor during the methylation cycle, which ensures the maintenance of adequate cellular levels of S-adenosylmethionine for its use in biological methylation reactions, including DNA methylation (12). Thus, folic acid deficiency may prevent normal methylation of epigenetically regulated genes (13). A number of previous studies have reported that folate levels are inversely associated with the risk 
of developing cervical cancer through the hypermethylation of $\mathrm{CpG}$ islands in certain tumor suppressor genes (14-16). However, to the best of our knowledge, methylation-mediated transcriptional repression of miRs regulated by folic acid has not been previously investigated in cervical cancer. Investigation of miR methylation provides a novel approach and insight for evaluating new molecules and mechanisms of progression in cervical cancer.

To evaluate the potential role of folate-associated miR methylation during the progression of CIN to cervical cancer, the present study assessed the expression of miR-203 and miR-375 in a range of tissues obtained from normal, CIN and cervical cancer cases. The population study and the experiments in cells demonstrated that folic acid is involved in the methylation of the CpG islands of miR-203 and miR-375. The results of the present study contribute to the understanding of the potential mechanism of cervical carcinogenesis induced by folate deficiency, which may lead to novel strategies for the prevention of CIN progression to cervical cancer.

\section{Materials and methods}

Patients and samples. Biopsy tissues were obtained from 90 women, with a median age of 32 years (range, 22-67 years), who were subjected to colposcopic examinations between January 2012 and January 2013 in the Department of Obstetrics and Gynecology of The Second Hospital of Shanxi Medical University (Taiyuan, China). According to the results of the pathological diagnosis of the cervical biopsies under colposcopy, patients in the study group were divided into CIN or stage IA-IIA cervical cancer (30 cases each). Patients with negative intraepithelial lesion or malignancy constituted the control group (30 cases). According to the 2009 International Federation of Gynecology and Obstetrics staging system (17), 15 cases of cervical squamous cell carcinoma (SCC) were stage Ia, 6 cases were stage Ib and 9 cases were stage IIa. According to the pathological classification (18), 4 cases were highly-differentiated, 24 cases were moderately-differentiated and 2 cases were poorly-differentiated cervical SCC. Among the patients with CIN, 5 cases were stage I, 15 cases were stage II and 10 cases were stage III. The staging of CIN were classified between CIN I and CIN III, according to Wright et al (19). Normal cervical tissues from the same period were obtained from the complete uterine hysterectomy practices on the patients.

All participants were Han Chinese and had been living in Shanxi for $>5$ years, and their diagnoses were confirmed by two pathological examinations. Participants with nutritional megaloblastic anemia, hemolytic disease, leukemia, liver disease, other tumors or who had been administered B vitamins within the 3 months prior to the study, were excluded. None of the patients received radiotherapy or chemotherapy prior to surgery. Upon obtaining written informed consent from all participants, uterine cervix tissue samples were obtained from the participants who underwent hysterectomy or biopsy under colposcopy, and immediately stored at $-80^{\circ} \mathrm{C}$. The present study was conducted in accordance with the Declaration of Helsinki, and was conducted with approval from the Ethics Committee of The Second Hospital of Shanxi Medical University (Taiyuan, China).
Cell culture. CaSki cervical cancer cells were purchased from the Cell Bank of Type Culture Collection of the Chinese Academy of Sciences (Shanghai, China), and preserved in the Department of Obstetrics and Gynecology of The Second Hospital of Shanxi Medical University. Cells were cultured in RPMI-1640 medium (Hyclone; GE Healthcare Life Sciences, Logan, UT, USA) supplemented with $10 \%$ (v/v) fetal bovine serum (Sijiqing; Zhejiang Tianhang Biotechnology Co., Ltd.; Huzhou, China) in a humidified $5 \% \mathrm{CO}_{2}$ incubator at $37^{\circ} \mathrm{C}$. Folic acid (Sigma-Aldrich, St. Louis, MO, USA) was used at final concentrations of $1,10,100,250,750$ and $1,000 \mu \mathrm{g} / \mathrm{ml}$. The cancer cell line was seeded $\left(3 \times 10^{5}\right.$ cells/well) into 6 -well plates (Corning Incorporated, Corning, NY, USA), and incubated overnight. Subsequently, cells were treated with folic acid at the aforementioned concentrations for $48 \mathrm{~h}$. Following $48 \mathrm{~h}$ of incubation, cells were harvested and used in subsequent experiments.

Reverse transcription-quantitative polymerase chain reaction $(R T-q P C R)$. RNA was isolated from patients' tissues using TRIzol ${ }^{\circledR}$ reagent (Invitrogen; Thermo Fisher Scientific, Inc., Waltham, MA, USA) according to the manufacturer's protocol, and the quantity and concentration of RNA were spectrophotometrically assessed (NanoDrop ${ }^{\mathrm{TM}}$ 2000; Thermo Fisher Scientific, Inc.) by ethidium bromide visualization (Sigma-Aldrich) of $28 \mathrm{~S}$ and $18 \mathrm{~S}$ ribosomal (r)RNA. The absorbance $(\mathrm{A})_{260} / \mathrm{A}_{280}$ ratio was determined to be in the 1.9-2.2 range, indicating no contamination (protein contamination, <1.9; DNA contamination, $>1.9$; NanoDrop ${ }^{\mathrm{TM}}$ 2000; Thermo Fisher Scientific, Inc.). For miR quantification, the Qiagen OneStep RT-PCR kit (Qiagen GmbH, Hilden, Germany) was used. Each RT reaction consisted of $2 \mu \mathrm{l}$ total RNA, mixed with $1.2 \mu \mathrm{l}$ primers, $10 \mu \mathrm{l} 2 \mathrm{X}$ buffer, $0.2 \mu \mathrm{l}$ Moloney murine leukemia virus reverse transcriptase and $6.5 \mu \mathrm{l}$ diethylpyrocarbonate-treated water in a final volume of $20 \mu \mathrm{l}$, and was incubated at $42^{\circ} \mathrm{C}$ for $30 \mathrm{~min}, 85^{\circ} \mathrm{C}$ for $10 \mathrm{~min}$ and maintained at $4^{\circ} \mathrm{C}$. DNase (Sigma-Aldrich) was used for degrading DNA. RT-qPCR was conducted in a StepOnePlus ${ }^{\mathrm{TM}}$ Real-Time PCR system (Thermo Fisher Scientific, Inc.) using SYBR Premix Ex Taq II (Tli RNase H Plus) (Takara Biotechnology Co., Ltd., Dalian, China). PCR was performed using the EpiTect Fast DNA Bisulfite kit (Qiagen $\mathrm{GmbH}$ ). Each PCR reaction contained $20 \mu \mathrm{M}$ forward primer, $20 \mu \mathrm{M}$ reverse primer, $10 \mu \mathrm{l}$ PCR Master Mix, $0.4 \mu 1$ Taq DNA polymerase $(2.5 \mathrm{U} / \mu \mathrm{l})$, and double distilled (dd) $\mathrm{H}_{2} \mathrm{O}$ to a final volume of $20 \mu \mathrm{l}$. The PCR conditions were as follows: An initial cycle at $95^{\circ} \mathrm{C}$ for $3 \mathrm{~min}$, followed by 40 cycles at $94^{\circ} \mathrm{C}$ for $12 \mathrm{sec}$ and $40 \mathrm{sec}$ at $62^{\circ} \mathrm{C}$. Primers were designed using the online bioinformatics tool MethPrimer (www.urogene.org/methprimer). The primers, whose sequence appears in Table I, were synthesized by Jima Corp. (Shanghai, China). The $2^{-\Delta \Delta \mathrm{Cq}}$ method (20) was used to determine the relative quantification of miR expression in the tissue samples. The levels of miR expression were normalized to the expression levels of 5S rRNA and represented as fold-change.

Methylation-specific PCR (MSP). MSP consists of two different PCRs that amplify a bisulfite-treated DNA sample using primers that are specific for methylated or unmethylated sequences (21). MSP was performed using the EpiTect MSP Kit (Qiagen $\mathrm{GmbH}$ ). The MSP reactions consisted of $0.35 \mu \mathrm{M}$ 
Table I. Primer sequences for amplification of miR-375, miR-203 and 5S rRNA.

\begin{tabular}{llc}
\hline Gene & \multicolumn{1}{c}{ Primer sequence, 5'-3' } & Product length, bp \\
\hline 5S rRNA & F: ACGGCCATACCACCCTGAAC & 91 \\
& R: GGCGGTCTCCCATCCAAGTA & 81 \\
hsa-miR-375 & F: CTTACTATCCGTTTGTTCGTTCG & 80 \\
hsa-miR-203 & R: TATGGTTGTTCTCGTCTCTGTGTC \\
& F: AACCTTGCTCGTGAAATGTTTAG & \\
& R: TATGCTTGTTCTCGTCTCTGTGTC & \\
\hline
\end{tabular}

F, forward; R, reverse; bp, base pairs; miR, microRNA; rRNA, ribosomal RNA; hsa, Homo sapiens.

primers, $25 \mu 1$ EpiTect Master Mix, $15 \mu 1$ target DNA and $\mathrm{ddH}_{2} \mathrm{O}$ to a final volume of $50 \mu \mathrm{l}$. The primer sequences for MSP were as follows: miR-375, methylated primers, sense, 5'-AGCGGCGTATAGTTTTTTTTATTC-3'; antisense, 5'-CGAACCTAAACGTTTTATTCGTT-3'; unmethylated primers, sense, 5'-CTTACTATCCGTTTGTTCGTTCG-3'; antisense, 5'-TATGGT TGT TCTCGTCTCTGT GTC-3'; miR-203, methylated primers, sense, 3'-TTGCGGAGAGAG GAGTTTTC-5'; antisense, 3'-CTACAACAAAACAAAAAA TACGCG-5'; unmethylated primers, sense, 3'-GAGTTGTGG AGAGAGGAGTTTTT-5'; antisense, 3'-CTACAACAAAAC AAAAAATACACAAC-5'. The reaction conditions were as follows: An initial cycle of $15 \mathrm{~min}$ at $95^{\circ} \mathrm{C}$, followed by 35 cycles of $15 \mathrm{sec}$ at $94^{\circ} \mathrm{C}, 30 \mathrm{sec}$ at $55^{\circ} \mathrm{C}$ and $30 \mathrm{sec}$ at $72^{\circ} \mathrm{C}$. The amplicons were evaluated on $8 \%$ agarose electrophoresis gel. The presence or absence of one of the amplicons was associated with the pattern of the target gene.

Statistical analysis. Statistical analysis was performed with SPSS version 16.0 (SPSS, Inc., Chicago, IL, USA). GraphPad Prism (GraphPad Software, Inc., La Jolla, CA, USA) was used to draw graphs in Fig. 1 and 3. Microsoft Excel 2010 (Microsoft Corporation, Redmond, WA, USA) was used to draw graphs in Fig. 2 and 4. Comparison between multiple sets of quantitative data was performed using single factor (also known as one-way) analysis of variance (ANOVA), while multiple comparisons between groups were performed using Fisher's least significant difference t test. Methylation rates were compared with $\chi^{2}$ test, and Pearson correlation test was used for correlation analysis. The experiments were all repeated three times. $\mathrm{P}<0.05$ was considered to indicate a statistically significant difference.

\section{Results}

Expression of miR-375 and miR-203. To identify whether miR-375 and miR-203 were potentially involved in the severity of cervical lesions, total RNA was isolated from normal tissues [which served as the negative control (NC)], CIN and SCC tissues. Using RT-qPCR, the expression of miR-375 and miR-203 was detected in NC, CIN and SCC tissue samples. Notably, the relative expression levels of miR-375 and miR-203 significantly differed between the NC, CIN and SCC groups $(\mathrm{P}<0.001$; Table II). Furthermore, miR-375 and miR-203 demonstrated lower expression in CIN and SCC, compared with NC.
Effects of folate on miR-375 and miR-203 expression. CaSki cells were treated with increasing concentrations of folate (1, $10,100,250,750$ and $1,000 \mu \mathrm{g} / \mathrm{ml})$. The expression levels of miR-375 and miR-203 in CaSki cells were detected by RT-qPCR following treatmen $t$ with folate. The results revealed that there was a significant difference in the expression levels of miR-375 and miR-203 in CaSki cells at various folate concentrations (one-way ANOVA; P<0.001) (Fig. 1). As indicated in Fig. 2, statistical analysis revealed that miR-375 and miR-203 were positively correlated with folate concentration (Pearson correlation test; $\mathrm{r}^{2}=0.963$ and 0.708 , respectively; $\left.\mathrm{P}<0.05\right)$.

Effects of folate on miR-375 and miR-203 methylation. MSP was used to detect the methylation status of miR-375 and miR-203 following treatment with various concentrations of folate. The results revealed that the positive rates of miR-375 and miR-203 methylation decreased gradually with increasing concentrations of folic acid $\left(\chi^{2}=25.696, \mathrm{P}<0.001\right.$ and $\chi^{2}=16.716$, $\mathrm{P}=0.006$; Fig. $3 \mathrm{~A}$ and $\mathrm{B}$, respectively).

Correlation analysis. Statistical analysis revealed that the expression levels and the methylation status of miR-375 and miR-203 were negatively correlated $\left(\mathrm{r}^{2}=0.788, \mathrm{P}<0.001\right.$; $r^{2}=0.875, \mathrm{P}<0.001$; Fig. 4A and B, respectively).

\section{Discussion}

Cervical cancer is the second most aggressive type of malignant tumor, and causes serious damage to women's health (22). Each year, there are $\sim 150,000$ newly diagnosed cases of cervical cancer in China, which accounts for almost $1 / 3$ of the total cases worldwide (12). Previous studies have identified that the occurrence of cervical cancer is associated with HPV infection, but is additionally influenced by other biological events (23). miR alterations have been demonstrated to have a significant role in various steps of tumor formation and progression (13). Similar to certain growth-suppressive protein-encoding tumor suppressor genes, certain miR genes harbor $\mathrm{CpG}$ islands, which are susceptible to methylation-mediated silencing (24). Therefore, hypermethylation-mediated silencing of tumor-suppressive miRs may be an important mechanism of tumorigenesis. To the best of our knowledge, only a small number of studies have investigated the methylation status of selected miRs, including miR-203 and miR-375, in cervical cancer (25). The present study evaluated 
Table II. Expression levels of miR-375 and miR-203 in tissues.

A, $\operatorname{miR}-375$

\begin{tabular}{lccc}
\hline Groups & Expression of miR-375 & $\mathrm{t}$ & P-value \\
\hline NC & $1.02 \pm 0.13$ & 42.732 & $<0.001$ \\
CIN & $0.04 \pm 0.02$ & -8.800 & $<0.001$ \\
SCC & $0.08 \pm 0.02$ & 40.869 & $<0.001$ \\
\hline
\end{tabular}

B, miR-203

\begin{tabular}{lccc}
\hline Groups & Expression of miR-203 & $\mathrm{t}$ & P-value \\
\hline NC & $1.00 \pm 0.17$ & 27.278 & $<0.001$ \\
CIN & $0.13 \pm 0.04$ & -13.789 & $<0.001$ \\
SCC & $0.27 \pm 0.03$ & 23.184 & $<0.001$ \\
\hline
\end{tabular}

Expression of miRs in the CIN and SCC groups is relative to the expression in the NC group, which is set at 1. Fisher's least significance test was used to calculate the t-value. P-values are comparisons between any two groups. miR, microRNA; NC, negative control; CIN, cervical intraepithelial neoplasia; SCC, squamous cell carcinoma.

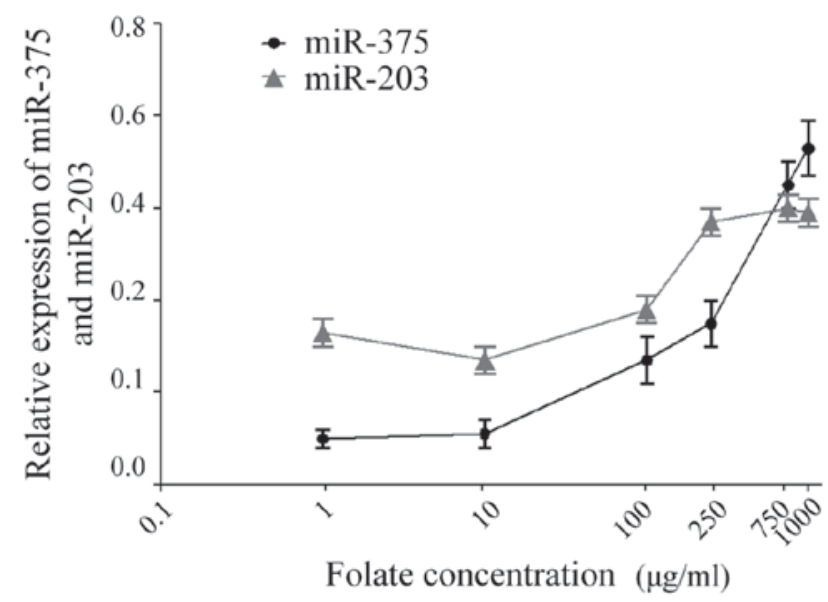

Figure 1. Effect of various folate concentrations on the expression of miR-375 and miR-203 in the CaSki cervical cancer cell line. Total RNA was purified from the cell pellets, and analyzed by reverse transcription-quantitative polymerase chain reaction in order to determine the expression levels of miR-375 and miR-203. The expression levels of miR-375 and miR-203 were normalized to those of $5 \mathrm{~S}$ ribosomal RNA. Data are presented as the mean \pm standard deviation of 3 experiments. miR, microRNA.

the expression of miR-203 and miR-375 in a range of tissues obtained from normal, CIN and cervical cancer cases, with the aim of determining their expression levels in uterine cervix premalignant and malignant lesions.

miR-203 has been reported to suppress cancer cell proliferation and invasion (26). miR-203 is downregulated in several types of cancer, including hematopoietic tumors (27). In the cervix, Cheung et al (24) conducted the first comprehensive miR expression profiling study in tissues from normal cervical epithelium ( $n=9$ ) and high-grade CIN (stage II, $n=12$ and stage III, $n=12$ ) tissues, in order to identify miR candidates with potential future clinical applications from a pool of $202 \mathrm{miRs}$.
The results demonstrated that miR-203 may be useful to distinguish high-grade CIN specimens from normal cervical epithelium (lower-bound of fold-change $>2$; $\mathrm{P} \leq 0.05$ ) (28). However, Gocze et al (29) used PCR to detect the expression of 8 different miRs in cervical cancer tissues, and observed that the expression levels of miR-203 were significantly higher in cervical cancer tissue samples, compared with normal tissues. Therefore, the expression of miR-203 in cervical cancer remains under debate. In the present study, it was observed that the expression levels of miR-203 in CIN and cervical cancer tissues were lower, compared with that of normal cervical tissue. The results of the present study were consistent with previous studies with regard to the global expression pattern of miRs in cervical dysplasia and cancer (30). Melar-New and Laimins (31) demonstrated that the E7 protein of high-risk HPV was able to block differentiation-induced miR-203 upregulation in human keratinocytes via the mitogen-activated protein kinase/protein kinase C signaling pathway. Greco et al (32) revealed that the E5 protein of high-risk HPV downregulated the expression of miR-203, and therefore may have a significant role in HPV infection and subsequent transformation through complex regulatory patterns of $\Delta \mathrm{Np} 63$ expression in the host cells. These previous observations may aid to explain the downregulation of miR-203 observed in the present study.

Alhough miR-375 has primarily been studied in the context of diabetes, as it influences $\beta$-cell mass and insulin levels, its expression has also been demonstrated to be decreased in several malignancies (33). Wang et al (34) used stem-loop RT-qPCR to detect the expression levels of miR-375 in cervical cancer tissues (170 cases) and normal cervical tissues (68 cases). The authors observed that, compared with normal cervical tissues, the expression levels of miR-375 in cervical cancer tissues were 4.45 times lower, and closely associated with poor prognostic factors of cervical cancer (34). Additional studies revealed that miR-375 expression was upregulated in cervical cancer cells following paclitaxel treatment in vitro, and in tissues following paclitaxel combination chemotherapy (35), which may be induced directly by targeting E-cadherin (36). However, to the best of our knowledge, the expression of miR-375 in cervical precancerous lesions has not been reported thus far. The results of the present study indicated that, compared with the control group, the expression levels of miR-375 in the CIN group were markedly decreased, suggesting that low expression levels of miR-375 may be involved in the process of carcinogenesis.

miR expression may be reduced by several factors, including transcriptional factors, mutations, deletions and methylation (37). However, the mechanism of downregulation of miR-203 and miR-375 in cervical cancer remains to be elucidated. Previously, Wilting et al (38) used MSP to analyze a cell line panel representing various stages of HPV-induced transformation, and revealed an increase in methylation of miR-203 and miR-375 with progression to malignancy. Furthermore, the expression of these miRs was restored following treatment with a demethylating agent (38). Additional experiments confirmed that the methylation levels of miR-203 and miR-375 were also significantly increased in high-grade CIN and cervical cancer samples, compared with normal tissues (38).

To the best of our knowledge, methylation-mediated transcriptional repression of miR-203 and miR-375 regulated by 


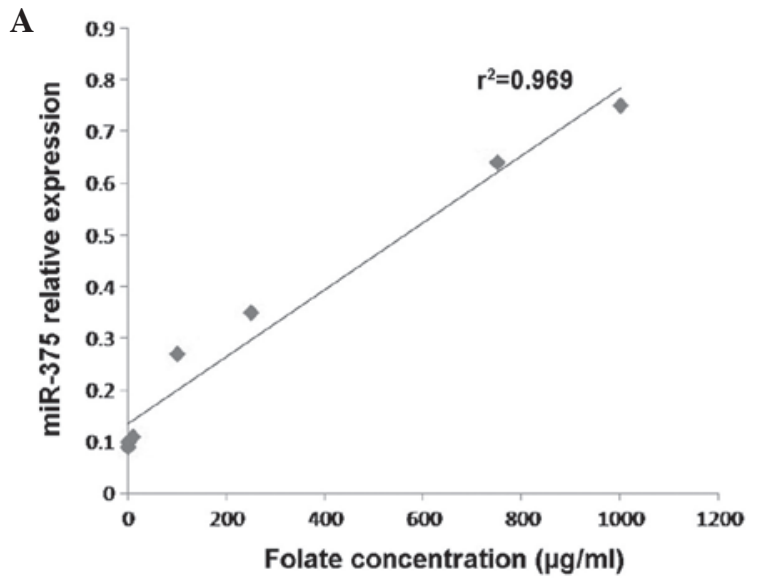

B

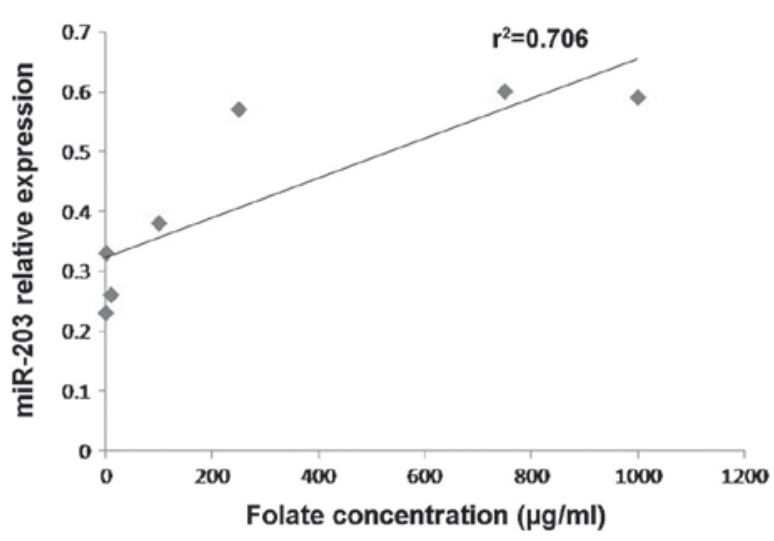

Figure 2. Positive correlation between the expression levels of (A) miR-375 and (B) miR-203 and folate concentration in CaSki cells. The concentrations of folic acid used to treat the cells were $1,10,100,250,750$ and $1,000 \mu \mathrm{g} / \mathrm{ml}$. The graphs are representative of 3 experiments. P $<0.05$ (Pearson's). miR, microRNA.

A

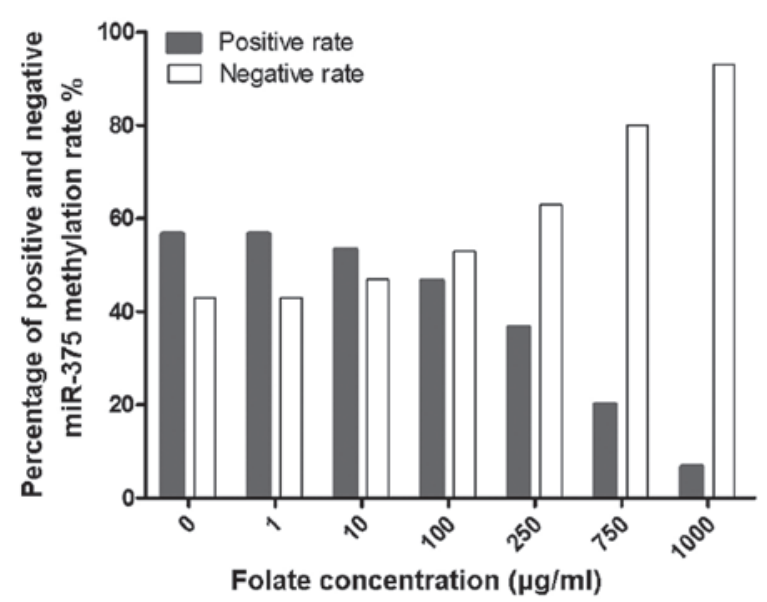

B

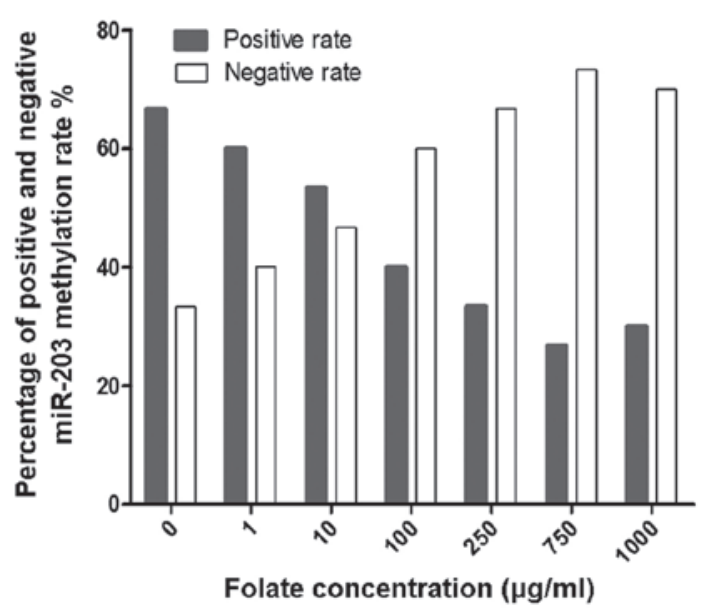

Figure 3. Percentage of positive and negative methylation rate (the number of methylated miR observed and counted) obtained for (A) miR-375 and (B) miR-203 by methylation-specific polymerase chain reaction analysis, following incubation of CaSki cells with various concentrations of folic acid. The experiment was performed 3 times. miR, microRNA.

A

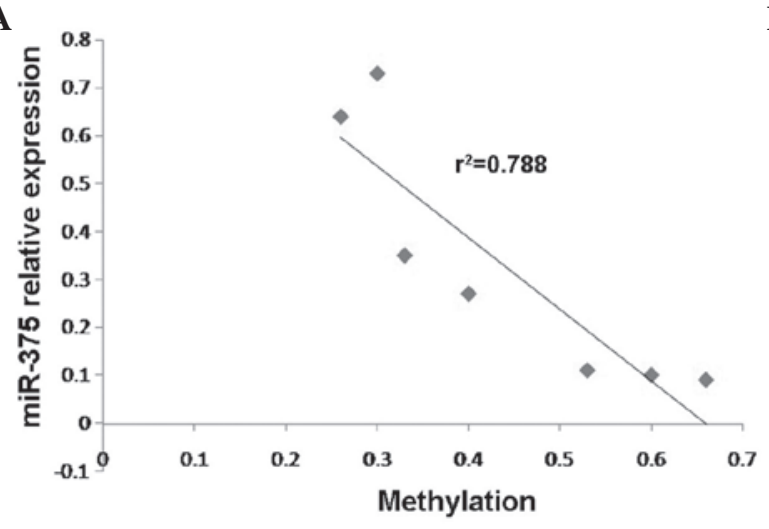

B

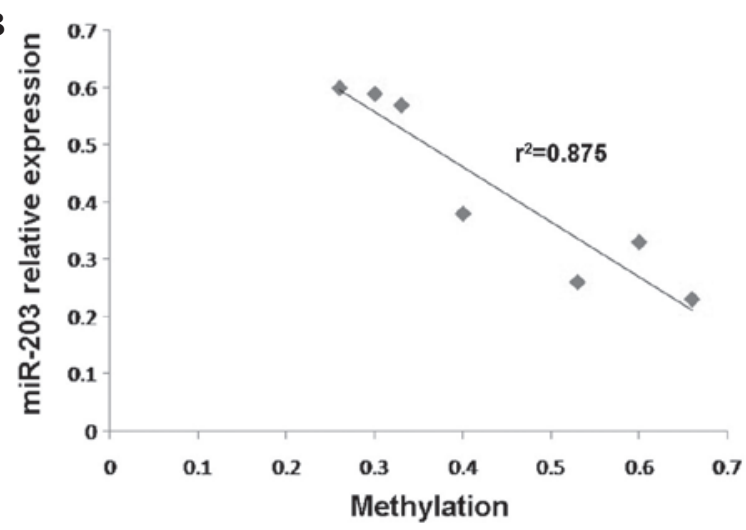

Figure 4. Negative correlation between the expression levels of (A) miR-375 and (B) miR-203 and their methylation status. The graphs are representative of 3 experiments. $\mathrm{P}<0.01$ (2-tailed). miR, microRNA.

folic acid has not been previously reported for cervical cancer. In mammals, folate is directly involved in DNA methylation by providing methyl groups (39). Therefore, the biological association between folate and methylation suggests that the influence of folate in cervical carcinogenesis may be associated with the alteration of miR expression via methylation of miR's CpG islands (40). To verify this hypothesis, the present study additionally examined the effect of elevated folate 
levels on the methylation rates of miR-203 and miR-375, and observed that with increasing folate levels in cervical cancer cells, miR-203 and miR-375 methylation decreased, while the expression of miR-203 and miR-375 increased. In addition, the methylation rate of the $\mathrm{CpG}$ island in miR-203 and miR-375 and the expression levels of miR-203 and miR-375 were highly negatively correlated, further confirming that the downregulation of miR-203 and miR-375 in the process of cervical carcinogenesis is associated with the high methylation rate of miR-203 and miR-375, which may be caused by a lack of folic acid.

In summary, to the best of our knowledge, the present study reports for the first time that folate deficiency may induce cervical carcinogenesis. Folate deficiency downregulates miR-203 and miR-375 expression via methylation of their $\mathrm{CpG}$ islands. However, the association between folate, methylation of miRs and cervical cancer remains to be fully elucidated, and the function and mechanism of these various components requires validation in future studies.

\section{Acknowledgements}

The present study was supported by grants from the Special Public Welfare Industry Research of the National Health and Family Planning Commission (Beijing, China; grant no. 201402010) and the Shanxi Health and Family Planning Commission Youth Project (Taiyuan, China; grant no. 201301015).

\section{References}

1. Ferlay J, Soerjomataram I, Dikshit R, Eser S, Mathers C, Rebelo M, Parkin DM, Forman D and Bray F: Cancer incidence and mortality worldwide: Sources, methods and major patterns in GLOBOCAN 2012. Int J Cancer 136: E359-E386, 2015.

2. Schiffman MH and Castle P: Epidemiologic studies of a necessary causal risk factor: Human papillomavirus infection and cervical neoplasia. J Natl Cancer Inst 95: E2, 2003.

3. Choi YJ and Park JS: Clinical significance of human papillomavirus genotyping. J Gynecol Oncol 27: e21, 2016.

4. Ho GY, Bierman R, Beardsley L, Chang CJ and Burk RD: Natural history of cervicovaginal papillomavirus infection in young women. N Engl J Med 338: 423-428, 1998.

5. Zhao WH, Hao M, Cheng XT, Yang X, Wang ZL, Cheng KY, Liu FL and Bai YX: c-myc gene copy number variation in cervical exfoliated cells detected on fluorescence in situ hybridization for cervical cancer screening. Gynecol Obstet Invest Jan 26: 2016 (Epub ahead of print)

6. Wilting SM, Snijders PJ, Verlaat W, Jaspers A, van de Wiel MA, van Wieringen WN, Meijer GA, Kenter GG, Yi Y, le Sage C, et al: Altered microRNA expression associated with chromosomal changes contributes to cervical carcinogenesis. Oncogene 32: 106-116, 2013

7. Bartel DP: MicroRNAs: Genomics, biogenesis, mechanism, and function. Cell 116: 281-297, 2004.

8. Wang L, Yue Y, Wang X and Jin H: Function and clinical potential of microRNAs in hepatocellular carcinoma. Oncol Lett 10: 3345-3353, 2015.

9. Lo R and Weksberg R: Biological and biochemical modulation of DNA methylation. Epigenomics 6: 593-602, 2014.

10. Sarkar D, Leung EY, Baguley BC, Finlay GJ and Askarian-Amiri ME: Epigenetic regulation in human melanoma: Past and future. Epigenetics 10: 103-121, 2015.

11. Wang LQ and Chim CS: DNA methylation of tumor-suppressor miRNA genes in chronic lymphocytic leukemia. Epigenomics 7: 461-473, 2015.

12. Ferlay J, Shin HR, Bray F, Forman D, Mathers C and Parkin DM: Estimates of worldwide burden of cancer in 2008: GLOBOCAN 2008. Int J Cancer 127: 2893-2917, 2010.
13. Wang JT, Ding L, Jiang SW, Hao J, Zhao WM, Zhou Q, Yang ZK and Zhang L: Folate deficiency and aberrant expression of DNA methyltransferase 1 were associated with cervical cancerization. Curr Pharm Des 20: 1639-1646, 2014.

14. Flatley JE, McNeir K, Balasubramani L, Tidy J, Stuart EL, Young TA and Powers HJ: Folate status and aberrant DNA methylation are associated with HPV infection and cervical pathogenesis. Cancer Epidemiol Biomarkers Prev 18: 2782-2789, 2009.

15. Flatley JE, Sargent A, Kitchener HC, Russell JM and Powers HJ: Tumour suppressor gene methylation and cervical cell folate concentration are determinants of high-risk human papillomavirus persistence: A nested case control study. BMC Cancer 14: 803, 2014.

16. Bai LX, Wang JT, Ding L, Jiang SW, Kang HJ, Gao CF, Chen X, Chen $\mathrm{C}$ and Zhou Q: Folate deficiency and FHIT hypermethylation and HPV 16 infection promote cervical cancerization. Asian Pac J Cancer Prev 15: 9313-9317, 2014.

17. Lewin SN, Herzog TJ, Barrena Medel NI, Deutsch I, Burke WM, Sun X and Wright JD: Comparative performance of the 2009 International Federation of Gynecology and Obstetrics' staging system for uterine corpus cancer. Obstet Gynecol 116: 1141-1149, 2010.

18. Liu HQ, Wang YH, Wang LL, Hao M: P16INK4A and survivin: Diagnostic and prognostic markers in cervical intraepithelial neoplasia and cervical squamous cell carcinoma. Exp Mol Pathol 99: 44-49, 2015.

19. Wright TC, Ronnett BM, Kurman RJ and Ferenczy A: Precancerous lesions of the cervix. In: Kurman RJ, Ellenson LH and Ronnett BM (eds). Blaustein's Pathology of the Female Genital Tract. 6th edition. Springer US, New York, NY, pp193-252, 2011.

20. Livak KJ and Schmittgen TD: Analysis of relative gene expression data using real-time quantitative PCR and the 2(-Delta Delta C(T)) Method. Methods 25: 402-408, 2001.

21. Xiao W, Zhao H, Dong W, Li Q, Zhu J, Li G, Zhang S and Ye M: Quantitative detection of methylated NDRG4 gene as a candidate biomarker for diagnosis of colorectal cancer. Oncol Lett 9: 1383-1387, 2015.

22. Shi JF, Canfell K, Lew JB and Qiao YL: The burden of cervical cancer in China: Synthesis of the evidence. Int J Cancer 130: 641-652, 2012.

23. Wang JT, Ma XC, Cheng YY, Ding L and Zhou Q: A case-control study on the association between folate and cervical cancer. Zhonghua Liu Xing Bing Xue Za Zhi 27: 424-427, 2006 (In Chinese).

24. Cheung TH, Man KN, Yu MY, Yim SF, Siu NS, Lo KW, Doran G, Wong RR, Wang VW, Smith DI, et al: Dysregulated microRNAs in the pathogenesis and progression of cervical neoplasm. Cell Cycle 11: 2876-2884, 2012.

25. Jiménez-Wences H, Peralta-Zaragoza $\mathrm{O}$ and Fernández-Tilapa G: Human papilloma virus, DNA methylation and microRNA expression in cervical cancer (Review). Oncol Rep 31: 2467-2476, 2014.

26. Yao T, Rao Q, Liu L, Zheng C, Xie Q, Liang J and Lin Z: Exploration of tumor-suppressive microRNAs silenced by DNA hypermethylation in cervical cancer. Virol J 10: 175, 2013.

27. Michel CI and Malumbres M: microRNA-203: Tumor suppression and beyond. Microrna 2: 118-126, 2013.

28. Chen T, Xu C, Chen J, Ding C, Xu Z, Li C and Zhao J: MicroRNA-203 inhibits cellular proliferation and invasion by targeting Bmil in non-small cell lung cancer. Oncol Lett 9: 2639-2646, 2015.

29. Gocze K, Gombos K, Juhasz K, Kovacs K, Kajtar B, Benczik M, Gocze P, Patczai B, Arany I and Ember I: Unique microRNA expression profiles in cervical cancer. Anticancer Res 33: 2561-2567, 2013

30. Gocze K, Gombos K, Kovacs K, Juhasz K, Gocze P and Kiss I: MicroRNA expressions in HPV-induced cervical dysplasia and cancer. Anticancer Res 35: 523-530, 2015.

31. Melar-New M and Laimins LA: Human papillomaviruses modulate expression of microRNA 203 upon epithelial differentiation to control levels of p63 proteins. J Virol 84: 5212-5221, 2010.

32. Greco D, Kivi N, Qian K, Leivonen SK, Auvinen P and Auvinen E: Human papillomavirus 16 E5 modulates the expression of host microRNAs. PLoS One 6: e21646, 2011.

33. Costa-PinheiroP, Ramalho-Carvalho J,VieiraFQ, Torres-Ferreira J, Oliveira J, Gonçalves CS, Costa BM, Henrique R and Jerónimo C: MicroRNA-375 plays a dual role in prostate carcinogenesis. Clin Epigenetics 7: 42, 2015. 
34. Wang F, Li Y, Zhou J, Xu J, Peng C, Ye F, Shen Y, Lu W, Wan X and Xie X: miR-375 is down-regulated in squamous cervical cancer and inhibits cell migration and invasion via targeting transcription factor SP1. Am J Pathol 179: 2580-2588, 2011.

35. Shen Y, Wang P, Li Y, Ye F, Wang F, Wan X, Cheng X, Lu W and Xie X: miR-375 is upregulated in acquired paclitaxel resistance in cervical cancer. Br J Cancer 109: 92-99, 2013.

36. Shen Y, Zhou J, Li Y, Ye F, Wan X, Lu W, Xie X and Cheng X: miR-375 mediated acquired chemo-resistance in cervical cancer by facilitating EMT. PLoS One 9: e109299, 2014.

37. Adams BD, Kasinski AL and Slack FJ: Aberrant regulation and function of microRNAs in cancer. Curr Biol 24: R762-776, 2014.
38. Wilting SM, Verlaat W, Jaspers A, Makazaji NA, Agami R, MeijerCJ, Snijders PJ and Steenbergen RD: Methylation-mediated transcriptional repression of microRNAs during cervical carcinogenesis. Epigenetics 8: 220-228, 2013.

39. Geng Y, Gao R, Chen X, Liu X, Liao X, Li Y, Liu S, Ding Y, Wang Y and He J: Folate deficiency impairs decidualization and alters methylation patterns of the genome in mice. Mol Hum Reprod 21: 844-856, 2015.

40. Ho E, Beaver LM, Williams DE and Dashwood RH: Dietary factors and epigenetic regulation for prostate cancer prevention. Adv Nutr 2: 497-510, 2011. 